noted and perhaps the remarkable translation from Purkinje's paper might have been commented on.

Galton's ample illustrations are not so well reproduced as might have been desired. For example, Figs. 7 and 15 are too heavily printed and Figs. 9 and 19 seem to be fading away. Otherwise the new book is well produced. At the present time, when many new data are becoming available on chromosomal aberrations associated with deformities which include alterations in papillary ridge patterns, it will be particularly useful to have this classical work easily available.

L. S. Penrose

\section{MODERN SURFACE COATINGS}

\section{Modern Surface Coatings}

A Textbook of the Chemistry and Technology of Paints, Varnishes, and Laequers. By Paul Nylén and Edward Sunderland. Pp. xiv +750 . (London and New York Interscience Publishers, a Division of John Wiley and Sons, 1965.) $147 s$.

GOOD index of the rate of development of a branch of science or technology is provided by the number of books published on it. There has been a great flowering of books dealing with surface coatings, especially paints, in the past five years or so, rightly reflecting the active technological development and the growing orientation towards a systematic and science-based approach to the subject. In addition to specialist monographs on specific subjects, there have also been several general treatments of the field, and Modern Surface Coatings must be judged in relation to these, as well as on its own merits.

The important part in surface coatings played by developments in raw materials is illustrated by the allocation of space in the present book; there are 275 pages on polymers and polymerization, 50 on solvents and plasticizers and 170 on pigments-almost 500 in all on raw materials, compared with 120 pages on pigment dispersion, film properties and paint application, and 80 pages on specific types of paint. While accepting the importance of raw materials, one would have liked to see fuller treatment of the problems specifically related to paint making and using, the sections on surface preparation and application methods being particularly limited.

This having been said, it is difficult to find fault with the book as a general introduction to paint science and technology, and it should prove invaluable to students everywhere; the sound approach doubtless owes much to the first-hand experience of the authors in teaching the subject at the Royal Institute of Technology in Stockholm. Emphasis throughout is placed on the scientific principles behind the subject, and the authors have-rightlylittle time for empiricism and the development of complicated formulations. As they say (p. 609) regarding the case of defects: "a thorough investigation and the use of a little physico-chemical imagination are much more likely to lead to a satisfactory and lasting solution". Readers need not expect, therefore, to find specific paint formulations in this book.

The general approach is to provide a balanced, eritical and up-to-date survey; also a much more international outlook than usual is provided, with references to publications and standards drawn freely from the major contributory countries-mainly the United States, Germany and Britain, supplemented by specific Scandinavian contributors where appropriate. Another refreshing and useful feature is the use made of trade names and references to trade literature, whenever this seems the best source of information.

Minor omissions are the absence of any reference to polyvinyl fluoride polymers, and the curious omission of zine silicates in the sections on inorganic and anti-corrosive paints, their treatment being restricted to anti-fouling paints. Only minor errors of fact were noted, and the whole book reads extremely well. References are numerous and up to date, one for 1965 being noted.

A better title would have been "Principles of Surface Coating Technology", but this was already pre-empted by the book by Parker from the same publishers; indeed, as Parker's book deals much more soundly with formulations than with principles, it is a pity the titles could not be reversed!

To sum up, Modern Surface Coatings should be of great value to students, lecturers and newcomers to the industry, and perhaps be educative even to established technologists. It is the best single-volume treatment of paint science and technology available to-day.

L. VALENTINE

\section{RUSSIAN FOR SCIENTISTS AND OTHERS}

Complete Russian Course for Scientists

By M. Beresford. Pp. xvii + 227. (Oxford: Clarendon Press; London: Oxford University Press, 1965.) 25s. net.

TOMPLETE Russian Course for Scientists is an excellent book and the key to its excellence lies in the fact that the title could easily have been "Complete Russian Course for Scientists and Others". There are a number of books in existence which elaim to purvey Russian for scientists, and in most of them there is little or no attempt to teach the language. The books are useful -in a very limited way - for the particular scientists the authors have in mind (chemists, physicists, geneticists, etc.). They are rarely helpful to scientists in general.

The book under review is a very different affair-." a rapid, intensive course, designed to enable beginners to master the essentials of Russian for reading purposes". The author, obviously interested in philology, has pro. duced a book which can be used not only by scientists and technologists, but by all students of Russian. It concentrates on the main features of Russian grammar and introduces scientific jargon gradually and progressively into the exercises, at first in the form of isolated phrases and then, in moderation, in the form of short texts.

The book contains twenty lessons (pp. 1-167), a supplement (pp. 171-193) containing eight divisions, including declension tables, tables of verbs, metric-English equivalents and a most useful list of Russian abbreviations, and finally (pp. 195-224) a select Russian-English vocabulary.

For the benefit of potential users of this book, here are a few notes on the contents of certain chapters. Lesson 1 , as one would expect, deals with the Russian alphabet and includes numerous exercises. Lesson 2 deals in a masterly fashion with pronunciation, a most important feature of the Russian alphabet, with hard and soft vowels, stressed vowels and consonants and like topies. Lesson 3 deals with the structure and derivation of words. Lessons 4-12 cover the cases of nouns and the tenses and aspects of verbs. Lessons 13-20 deal with an important selection of topies-Russian names, pronouns, particles, participles, numerals, fractions, gerunds. compound words, suffixes and roots.

It will be clear from this brief review of the contents that this book gives all the grammar necessary to provide an adequate background for a reading knowledge of the language, and this is supplemented by appropriate exercises. Two final points for the reader who wants to get full value from the book-the Russian alphabet is very necessary for constant reference during the early stages of the course. A spare copy on a card, which could easily be moved from page to page, would facilitate such reference. The second point is in the nature of a warning. This is not a book to be read through. It calls for hard work and determination, but the author has done his best to make such hard work and determination a good investment.

S. I. TOMK EIEFF 